\title{
Ficar, migrar e disputar o futuro
}

\author{
ANGELA FACUNDO NAVIA \\ Universidade Federal do Rio Grande do Norte, Natal, Rio Grande do Norte, Brasil
}

DOI 10.11606/issn.2316-9133.v28i2p21-25

Duas dinâmicas, amiúde desconexas nos estudos antropológicos, têm se intensificado nas últimas décadas no mundo e parecem estar também se agudizando no Brasil depois das últimas eleições presidenciais. As pessoas deslocadas ou desterradas, como preferia chamálas Alfredo Molano (2001), são a lembrança permanente de que o direito à terra, à moradia, aos alimentos, à vida digna e tranquila em diversas regiões do planeta é um privilégio de alguns. Espólio de terras de populações tradicionais pelo agronegócio e pela indústria do turismo, deslocados por grandes empreendimentos que destroem a própria possibilidade da vida, desastres ambientais irreparáveis, populações sob o fogo permanente de operações militares e perseguições individualizadas contra lideranças sociais tornaram-se experiências permanentes do nosso tempo e não mais exceções.

Simultaneamente, como seu avesso constitutivo, o movimento das pessoas é objeto de controles a cada dia mais evidentes e mais violentos. Algumas vezes pela presença ostensiva de forças securitárias como no caso da militarização das fronteiras internas e externas do estado e da nação, da expansão dos centros de internação de refugiados e migrantes e, de forma geral, do fortalecimento do complexo industrial fronteiriço. Outras vezes pela ação omissa, por meio da proibição e do descaso, como no caso dos milhares de náufragos largados à sorte e à morte (no Mar Mediterrâneo, no Rio Grande, no Estreito do Darien), da espera interminável por documentação e existência jurídica que suportam os solicitantes de refúgio nos países mais ricos, da exploração de mão de obra migrante indocumentada com a cumplicidade dos governos ditos democráticos e de tantas outras situações de dominação e extermínio que o enquadramento e o apagamento social e mediático nos dificultam reconhecer, no sentido proposto por Butler $(2015)^{1}$.

A insistência nos mecanismos mais cruéis de lucro, por meio do espólio e do controle migratório, não tem a intenção de que percamos de vista a importância do desejo de se movimentar e de migrar. A vontade das pessoas que empreendem projetos migratórios deve ser defendida como um direito bem como a própria noção de desejo resgatada das tentativas

\footnotetext{
${ }^{1}$ Para Butler (2015) existem modos culturais que regulam as respostas afetivas e éticas por meio de um enquadre seletivo e diferencial da violência. Os recortes através dos quais uma vida nos é apresentada orientam nossa capacidade de apreendê-la como uma vida e de nos comover com sua precariedade. Os enquadramentos são parte fundamental da dinâmica do reconhecimento de uma vida como viva.
} 
de desumanização das populações deslocadas, ou em trânsitos motivados pela precarização, que são costumeiramente representadas sem anseios, projetos ou sonhos e cujas potências vitais e políticas são habitualmente desconsideradas. Porém, é imperativo também reconhecer a imensa desigualdade planetária na hora de concretar os desejos tanto de permanência quanto de movimento. Já sem surpresa percebemos que quase sempre são as mesmas populações: as mais pobres, as mais racializadas, as indígenas (e as mulheres, a pessoas LGBTI, as pessoas com deficiência, as crianças e os idosos nesses grupos) as que mais sofrem com os rigores tanto da impossibilidade de ficar, quanto da impossibilidade de se movimentar livremente. O proposital "quase sempre" da frase anterior tem por intenção lembrar que os pertencimentos identitários nas nossas vidas são múltiplos e não poucas vezes conflitantes ou contraditórios. As categorias que nos atravessam não se aglomeram em somatória, mas se ativam a depender das experiências concretas de migração, trânsito ou luta pela permanência nos territórios, e das capacidades das pessoas para responderem criativamente e resistirem aos diversos regimes de controle, opressão e espólio.

No Brasil, no que tange às populações migrantes e refugiadas, a administração desses grupos não tem adquirido os formatos flagrantemente cruéis e torturantes do poder estatal que adotaram em outras latitudes do planeta (BROWN, 2010). Mas, algumas mudanças legislativas, assim como o possível efeito de contradição que as leis provocam quando colocadas em diálogo, nos alertam para um avanço da lógica securitária em vários níveis. As políticas de refúgio, comandadas pela Lei $\mathrm{n}^{\circ}$ 9.474, de 22 de julho de 1997, continuam baseadas em preceitos da ação humanitária internacional e dos direitos humanos, resguardando a linguagem de proteção de uma época em que o governo brasileiro tentava se desvencilhar da imagem de torturador projetada internacionalmente durante a ditadura. Porém, a efetivação dos conteúdos da lei não tem sido simples e, dentre outros efeitos da sua tradução em políticas concretas, podemos citar o foco nas políticas de recepção e a quase inexistência de políticas de acolhimento e de permanência, a polêmica ação de escolha e separação entre migrações econômicas e migrações provocadas por "fundados temores de perseguição" (BRASIL, 1997), o reduzido número de pessoas reconhecidas com o status de refugiadas (a pesar do aumento significativo nos últimos anos) e o uso da figura do refúgio como arma nas disputas no âmbito da política internacional. Esse último aspecto ficou mais evidente na recente insistência governamental em falar sobre o êxodo venezuelano que chegou ao Brasil em termos de refúgio, apesar de não estar disposto, até agora ${ }^{2}$, a dar esse

\footnotetext{
${ }^{2}$ Em 5 de dezembro passado, quando a primeira versão desse texto já tinha sida envida, o governo brasileiro decidiu reconhecer 21.432 venezuelanos como refugiados. Grupos da sociedade civil que trabalham sobre migração e refúgio comemoraram a decisão que aliviará a incerteza de milhares de pessoas que até então não sabiam o que iria acontecer com eles e elas em termos de documentos e permissões. A documentação é uma porta para usufruir de muitos dos benefícios do estado-nação de acolhida e o número de reconhecimentos é uma cifra inédita, que representa o dobro do total de concessões de asilo desde 1997. Os desdobramentos políticos do reconhecimento da "grave e generalizada violação de direitos humanos na Venezuela" ainda estão por vir e a avaliação dos entraves concretos da medida só poderão ser avaliados no futuro. Por exemplo, as
} 
reconhecimento de maneira efetiva para a maioria das pessoas oriundas do país vizinho, que terminam ativando outras categorias migratórias e, desse modo, sendo administradas com outras configurações legais, como a lei de migração.

A chamada "nova lei de migração" (Lei no 3.445, de 2017) foi comemorada por setores da sociedade civil que há décadas lutavam pela superação do Estatuto do Estrangeiro (Lei $\mathrm{n}^{\circ}$ 6.815, de 19 de agosto de 1980), cujo texto estava baseado na doutrina da "segurança nacional" própria da época de sua promulgação. As ações da sociedade civil e de alguns representantes políticos aliados estavam orientadas pela busca de harmonização das leis migratórias com a Constituição de 1988. Contudo, a aparente vitória deixou um sabor agridoce, como apontado por Bela Feldman-Bianco, especialista no assunto (2018). Notadamente depois dos vetos à lei, realizados pelo então presidente Michel Temer, o caráter humanitário que tinha sido defendido por organizações da sociedade civil cedeu espaço para uma visão ainda mais securitária e criminalizante da migração. Igor Machado (Comunicação oral, 2019) apontou recentemente ${ }^{3}$ alguns dos aspectos mais preocupantes tanto da lei original, quanto da sua versão piorada depois dos vetos. Para o autor, a lei que já tinha o problema de excluir o Conselho Nacional de Imigração (CNIg), deixou, depois dos vetos, como única autoridade efetiva a Polícia Federal. Uma perspectiva securitária da migração, que também autoriza a prisão por motivos migratórios, se complicou, ainda mais, com a perda da noção ampla de família, que permitiria políticas migratórias mais generosas de reunificação familiar, e com a eliminação dos dispositivos de proteção à migração transfronteiriça, particularmente importantes para os movimentos das populações indígenas que poderiam usufruir do direito de livre trânsito nos territórios históricos de existência e troca das suas populações.

Com o ânimo de reforçar a relevância acadêmica e política de reconectarmos os diversos regimes de controle e policiamento da vida que vêm crescendo e se encorpando nas últimas décadas, Natália Padovani sagazmente chama nossa atenção para a necessidade de pensarmos simultaneamente outras leis. Além da lei de migração, Natália nos alerta para a lei de "repressão ao tráfico de pessoas" (Lei no 13.344, de 6 de outubro de 2016) e para a lei sobre "organização criminosa" (Lei no 12.850, de 2 de agosto de 2013) ${ }^{4}$. A sanção desses "três dispositivos legais voltados para o controle das fronteiras nacionais brasileiras", em um lapso de seis anos, aponta também, ainda acompanhando a autora, para uma reconfiguração nas diretrizes que guiam a compreensão e as políticas em termos de segurança pública. Os enquadramentos criados por essas leis são bastante limitados e produzem também imagens

exigências de documentos que atestem nacionalidade, certidão de não ter antecedentes penais, não ter residência temporária e ser maior de 18 anos.

${ }^{3}$ Comunicação oral de Igor José de Renó Machado apresentada em outubro de 2019 na 43a Reunião da Anpocs na mesa redonda 35: "Políticas migratórias no Brasil contemporâneo: desafios, retrocessos e perspectivas" que ele coordenou.

${ }^{4}$ Comunicação oral de Natália Corazza Padovani apresentada em 3 de julho de 2019 no workshop "Migration, trafficking, sex work and the Law” (Migração, tráfico, trabalho sexual e a Lei) no Núcleo de Estudos de Gênero PAGU da Unicamp. 
antagônicas de vítimas e algozes que estão longe de compreender os complexos arranjos e estratégias das pessoas que decidem ou se veem obrigadas a migrar, como também tem sido assinalado por Adriana Piscitelli e Laura Lowenkron (2019). Finalmente, a Lei No 13.260, de 16 de março de 2016, nos ajuda a completar o quadro do alinhamento do Brasil com as políticas globais de combate ao tráfico de drogas e ao terrorismo internacional que foi salientado por Padovani. Dita lei, que reformula o conceito de organização terrorista, inclui no bojo legal do controle securitário também as populações locais que, mesmo sem intenções ou experiências migratórias, passam a sofrer, ainda com mais veemência, da restrição de direitos, incluindo o da circulação pelos seus territórios, justificada pela luta internacional contra o terrorismo.

$\mathrm{Na}$ experiência contemporânea de diferentes democracias continentais, olhando, por exemplo, o contexto Latino-americano, vemos que, em nome da luta contra o terror, o terror é implantado, em nome do combate à criminalidade, os crimes de Estado são aceitos e comemorados, em nome da proteção às vítimas, criminalizam-se os trânsitos e os arranjos que os permitem. Populações migrantes pobres, moradores de favelas e periferias urbanas, populações indígenas, sem teto e sem-terra que reclamam e lutam pelo direito à permanência nos territórios, à liberdade de locomoção e à construção e manutenção de formas próprias de vida são enquadradas e representadas como inimigas da segurança nacional e do Estado. Ao mesmo tempo, em nome da sua salvaguarda se justifica o desdobramento da violência letal e dos diversos mecanismos que impossibilitam a vida, a sanidade mental e a construção de projetos comunitários de futuro.

Em comum, além dos marcos normativos que enquadram sujeitos e práticas na compreensão restrita de criminosos e vítimas, está, me parece, a construção de um alvo privilegiado para o extermínio físico e simbólico das comunidades: as crianças. Em alguns dos cenários contemporâneos que são emblemáticos dos controles securitários das fronteiras, da militarização dos territórios e do espólio as cenas de meninas e meninos assassinados, encarcerados, submetidos a julgamentos e execuções sumárias têm desafiado a nossa compreensão e a nossa sensibilidade sobre a infância, que são em parte produto de pactos morais e legais, tanto locais quanto internacionais. Um limite que se transpõe cotidianamente nas jaulas norte-americanas que capturam crianças separadas das suas famílias, na perseguição, encarceramento e extermínio sistemático de crianças palestinas nas mãos do exército de Israel, no número imenso e ignorado de meninos e meninas atingidas por balas das operações militares nas favelas do Rio de Janeiro, nos campos na Colômbia ou nos corpos afogados de bebês que também empreenderam as travessias internacionais junto com pais e parentes.

A transposição desse limite moral não me parece um acaso. Sem poder afirmar etnograficamente sua intencionalidade ou sistematicidade em todos os locais em que ele tem se manifestado, podemos e devemos, porém, refletir sobre suas consequências. Uma delas, por sua capacidade de atingir o futuro, pode ser pensada como uma ferramenta de guerra que antecipa a vitória negando a existência no porvir dos grupos que no tempo presente se 
batem pela sua existência, pelo direito de ir e vir e pelo direito de ficar. A impossibilidade do futuro como arma não se restringe às populações deslocadas ou em trânsito, mas parece ser uma constante em diversos contextos e locais do planeta que tem como um dos seus efeitos forçar o deslocamento ou a estagnação das pessoas mais precarizadas, tanto quanto inabilitar os territórios para a vida do jeito que ela é vivida pelas comunidades.

\section{Referências Bibliográficas}

BRASIL. Lei $\mathrm{n}^{\circ}$ 13.344, de 6 de outubro de 2016- Dispõe sobre prevenção e repressão ao tráfico interno e internacional de pessoas e sobre medidas de atenção às vítimas. Brasília, Subchefia de Assuntos Jurídicos, 2016.

. Lei no 12.850 , de 2 de agosto de 2013 - Define organização criminosa e dispõe sobre a investigação criminal, os meios de obtenção da prova, infrações penais correlatas e o procedimento criminal. Brasília, Subchefia de Assuntos Jurídicos, 2013.

Lei No 9.474, de 22 de julho de 1997 - Define mecanismos para a implementação do Estatuto dos Refugiados de 1951. Brasília, Subchefia de Assuntos Jurídicos, 1997. Lei No 6.815, De 19 De Agosto De 1980 - Define a situação jurídica do estrangeiro no Brasil, cria o Conselho Nacional de Imigração. Brasília, Subchefia de Assuntos Jurídicos, 1980.

BROWN, Wendy. Walled States, Waning Sovereignty. New York: Zone Books, 2010.

BUTLER, Judith. Quadros de Guerra: quando a vida é passível de luto? Tradução de Sérgio Lamarão e Arnaldo Cunha. $1^{\text {a }}$ ed. Rio de Janeiro: Civilização Brasileira, 2015.

FELDMAN-BIANCO, Bela.. "O Brasil frente ao regime global de controle das migrações: Direitos humanos, securitização e violências”. TRAVESSIA - Revista do Migrante, Ano XXXI, No 83, pp. 11-36, 2018

MOLANO, Alfredo. Desterrados: crónicas del desarraigo. Bogotá: Áncora editores, 2001.

PISCITELLI, Adriana; LOWENKRON, Laura. "Trabalhadoras/es migrantes e o tráfico internacional de pessoas em dois lados do oceano". In: Facundo et al (orgs) Pessoas em movimento. Práticas de gestão, categorias de direito e agências. pp. 135-171. Rio de Janeiro: Fundação Casa de Rui Barbosa e 7Letras, 2019.

autora

\section{Angela Facundo Navia}

É professora adjunta do Departamento de Antropologia e do PPGAS da Universidade Federal do Rio Grande do Norte. É graduada em Antropologia (UNC), mestra em Ethnoligie et Anthropologie sociale (EHESS) e doutora em Antropologia Social (MN-UFRJ). 